\title{
The Optimization of FDM 3D Printer`s Structure Based on Finite Element Analysis
}

\author{
Zhenhai Huang ${ }^{1}$, Tingchun Shi ${ }^{1}$ Xiuyan Yue ${ }^{2}$ \\ ${ }^{1}$ Hangzhou Dianzi University, Hangzhou, China \\ ${ }^{2}$ Hangzhou Dianzi University Library, Hangzhou, China
}

\begin{abstract}
In view of the forming accuracy of the 3D printer, the paper, from the structure of the printer itself, discussed the influence on the precision of the printer via improving the structure of 3D printer. A typical 3D printer, such as a common type of FDM, was selected, and SOLIDWORKS software was used for solid modeling, after establishing the model, the finite element analysis was carried out on the whole structure model to obtain the deformation characteristics and the main vibration model of the printer. On the basis of finite element analysis, the influence of the level shaft bearing diameter, material properties and symmetry of the parts on the overall mechanical properties of the printer was discussed respectively. On this basis, the overall structure of the machine has been optimized and achieved remarkable results.
\end{abstract}

\section{Introduction}

Fused deposition modeling (FDM) technology 3D printer has been widely applied in the market due to its high forming precision, low price and easy to obtain printing materials. Although FDM technology tends to mature, there are still many limitations in the process of forming and manufacturing such as molding precision, material type and so on. The factors that affect the forming precision of FDM type 3D printer can be divided into layered software, control algorithm, mechanical structure and so on. At present, the printer mechanical structure research mainly focus on the nozzle, column and other single parts of the analysis, relatively, on the overall structure of the $3 \mathrm{D}$ printer, is lack of integrity, and the research depth is not enough[1,2].

In this paper, a common Prusal3 series 3D printer is selected as the research object. Firstly, the overall model of the 3D printer is modeled. Secondly, the static mechanical analysis and dynamic mechanical analysis of the established printer model were carried out by using ANSYS Workbench software to get the deformed cloud chart, natural frequency and modal shape of the printer model. Finally, the result of the finite element analysis is used as a reference to optimize the mechanical structure of the printer.

\section{3D printer finite element model establishment}

\subsection{The establishment of CAD model for 3D printer}

The PrusaI3 series is one of the more popular FDM 3D printers available on the market[ 3,4$]$. The advantages of these printers are their simple mechanical structure and high precision. The printer's nozzle system includes the feeding and melting function, during the operation of the printer, which moves along the fixed shaft bearing. The modeling platform is located on the bottom shaft bearing of the 3D printer, and the motion direction of the platform is perpendicular to the motion plane of the nozzle system.

In order to accurately reflect the real situation of the printer, the SOLIDWORKS software is used to model the overall structure of the 3D printer in accordance with its actual size. In the process of modeling, according to the degree of impact on the subsequent finite element analysis, the printer structure is simplified. The two side screw bearing of 3D printer can be replaced by the same standard cylindrical shaft bearing, the synchronous belt is omitted and the stepper motor is simplified with a motor model of the same weight and shape. The simplified mode of the 3D printer overall structure and its main components are illustrated as shown in Figure 1. 


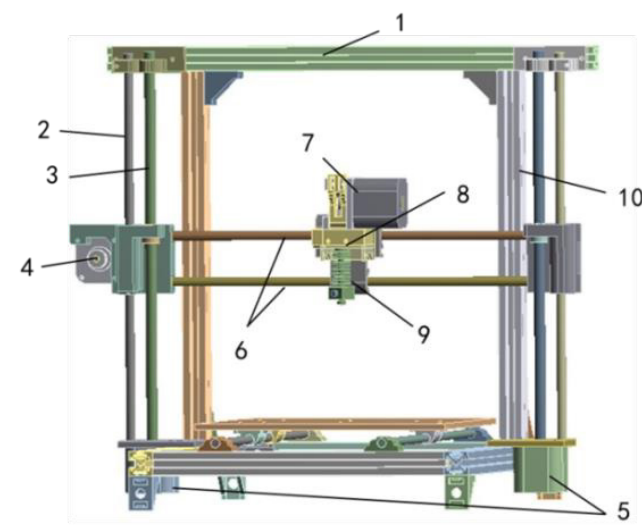

Figure 1. Simplified model of 3D printer

1.beam, 2. vertical shaft bearing, 3. simplified screw, 4, 5 . stepper motor, 6 . level shaft bearing, 7. feed motor, 8 . measuring points, 9 . nozzle melting part, 10 . columns.

\subsection{The material attribute setting of the model}

The rack part of 3D printer is mainly made up of aluminum alloy material. The type of aluminum alloy is 6060-T5 [5],the link between the two aluminum profiles is a fixed tripod, and the material is also aluminum alloy. In order to facilitate calculation, we set up the material property uniformly. The diameter of vertical and level shaft bearing of the 3D printer is $8 \mathrm{~mm}$, and the material is GCR15 bearing steel[6]. In the printer, the connecting part of the motor, the fixed nozzle part, and the part of the fixed level shaft bearing are the components with the material PLA[7]. The properties of GCR15 alloy steel materials, MJ-6-2020 aluminum alloy materials, PLA and other materials, as shown in Table 1.

Table 1.3D printer frame main material properties

\begin{tabular}{cccc}
\hline \hline $\begin{array}{c}\text { Type of } \\
\text { material }\end{array}$ & Density $\left(\mathrm{Kg} / \mathrm{m}^{\wedge} 3\right)$ & $\begin{array}{c}\text { Poisson } \\
\text { ratio }\end{array}$ & $\begin{array}{c}\text { Modulus of } \\
\text { elasticity }\end{array}$ \\
\hline $\begin{array}{c}\text { bearing steel } \\
\text { Aluminium }\end{array}$ & 7810 & 0.3 & $208 \mathrm{Gpa}$ \\
$\begin{array}{c}\text { alloy } \\
\text { PLA }\end{array}$ & 2700 & 0.33 & $70 \mathrm{Gpa}$ \\
\hline \hline
\end{tabular}

\subsection{Simplification of the contact surface of the model}

The processing method of the mechanical contact surface is important for the mechanical structure; the contact surface of the printer model can be roughly divided into fixed contact and non-separation contact. Fixed contact is suitable for objects with the same way of motion, the two objects cannot be separated or slipped. For the non-separation contact, it could have gaps that can rotate, but not allow lateral movement.

The aluminum section is linked by a tripod and is screwed through a M5*8 type screw. The size of the pre-tightening force is $6.4 \mathrm{kN}$. The frame of the $3 \mathrm{D}$ printer structure can be well fixed, and the contact with fixed screws on the printer structure can be treated as fixed contacts. For the printer nozzle system and the forming platform, the contact surface connected with the level shaft bearing is in a slippery state during the movement of the printer; however, in the static situation, there is a large sliding resistance on both sides and the resistance of the motor itself and the movement is difficult. In the subsequent finite element analysis, it is more convenient to treat it as a non - separation contact. In addition, in the analysis of the whole 3D printer structure, in order to simplify the calculation, the stepper motor model under the forming platform can be removed.

\section{Finite element analysis of $3 d$ printer structure}

Before the computation of finite element analysis, the mesh of the printer model needs to be divided, which is an important part of finite elements $[8,9]$. The quality of mesh will affect the transmission of force in the process of finite element calculation, which may ultimately affect the accuracy of calculation results. Under the default conditions of ANSYS workbench software, the quality of the grid obtained is relatively rough, and the grids between the various components have a larger difference. There are more grid division methods in the finite element analysis software. The mechanical part has a regular shape. When the mesh is optimized, the hexahedron-dominant method is used to optimize the mesh. The average quality of the mesh obtained after optimization is $73.6 \%$. The main purpose of finite element analysis is to explore the stability of 3D printer's mechanical structure, and the finite element analysis of the whole $3 \mathrm{D}$ printer structure can be mainly divided into the statics analysis and modal analysis.

\subsection{Statics analysis of 3D printer structure}

In the forming process of the $3 \mathrm{D}$ printer, the direct forming error comes from the stability of the nozzle system[10]. The nozzle system is divided into the melt forming system and the feeding system. The melt forming system is responsible for the melting and wiring of the molding material. Feeding system is located above the melt forming system and consists of feeding stepper motor and feeding model, which is responsible for material feeding work. The supporting part of the whole nozzle system is the two level shaft bearings which is connected to the nozzle system by a linear bearing.

The main purpose of static analysis is to analyze the reliability of the mechanical structure of the 3D printer and to discuss the potential defects in the structure of the printer. In the statics analysis of the finite element, the bottom of the four aluminum alloy tripod under the printer is fixed. After completing the boundary condition setting and grid optimization of the printer, the static analysis results of the printer under its own gravity are shown in Figure 2. 
(a)

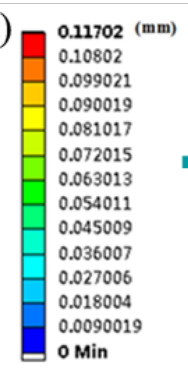

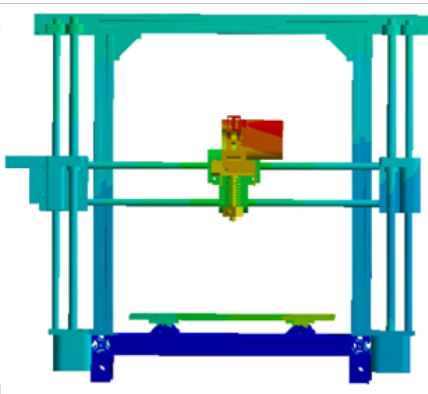

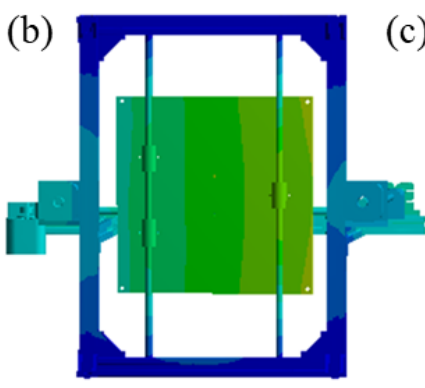

(c)
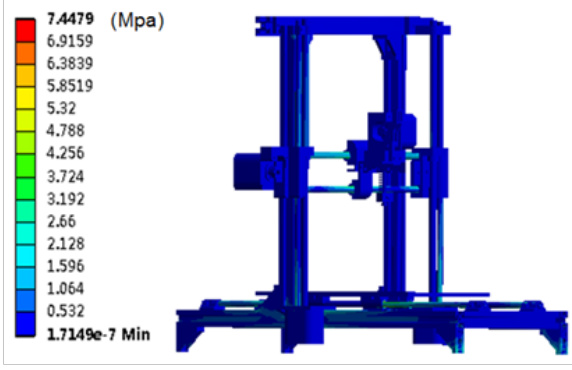

Figure 2. (a) Static analysis of the overall deformation of the front view and (b) Static analysis of the bottom view, and (c) The pressure distribution of static analysis

In the static analysis results of finite element, Fig. 2(c) is the pressure distribution chart, from which it can be seen that the main load-bearing parts of the printer are distributed in the contact parts between the bottom bracket and the column, as well as the contact part of the modeling platform and the nozzle system with its optical axis. The overall deformation of the 3D printer as shown in Fig.2(a), the printer structure has the largest amount of deformation at the feeding system, the tendency of deformation is to extend outwards from the fixation of the level shaft bearings, and the shape variable presents an increasing form, and the maximum deformation reaches $0.117 \mathrm{~mm}$. As can be seen from Fig.2(b), the deformation of the forming platform shows an asymmetrical trend. The deformation of the lower side is about $0.01 \mathrm{~mm}$, while the upper side reaches $0.06 \mathrm{~mm}$. At present, the nozzle diameter of the FDM type 3D printer on the market is generally $0.3-0.4 \mathrm{~mm}$, and the maximum precision of the printer can reach $0.1 \mathrm{~mm}$. In addition, in actual conditions, since the printer's molten nozzle is not firmly fixed, there may be a small swing in the forming of the printer. Considering the influence of these factors, the overall structural deformation of the 3D printer in static analysis will have a great influence on the molding error.

\subsection{Modal analysis of 3D printer structure}

In the working environment of the $3 \mathrm{D}$ printer, the excitation is dynamically loaded, and it should be avoid coupling the natural frequency with the external excitation[11-13]. When the mechanical structure of the coupling frequency is reduced, it can not only improve the stability of the printer itself, but also reduce the load of the machine itself and extend its service life. In the work of 3D printer, the main source of excitation is generated by stepper motor, which is at a relatively low level. In the modal analysis of the 3D printer, the vibration characteristics and natural frequency of the first to fourth orders are selected, and the modal analysis results of the whole structure of the printer are shown in Fig.3
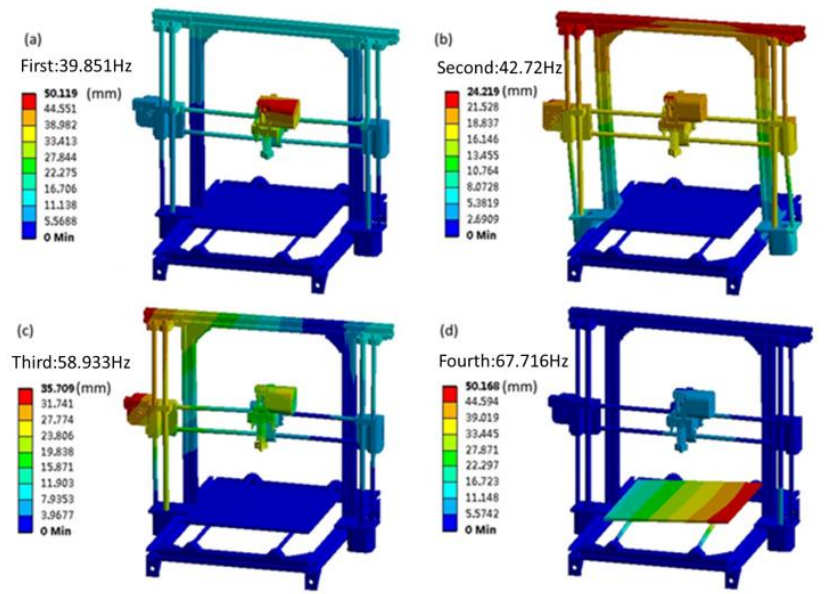

Figure 3. Modal analysis of the overall structure of 3D printer

It can be seen from the results of the modal analysis that the range of modal frequencies from the first to fourth orders is within $39-68 \mathrm{hz}$. When the frequency is low, the printer has obvious vibration phenomenon, such as the both sides of printer columns, beam parts, and nozzle system. When these analysis and optimization are carried out, we should make reasonable optimization for these parts.

\section{Optimal design of mechanical structure}

In general, the principle of mechanical structure optimization is to improve the natural frequency of the mechanical structure and avoid the occurrence of frequency coupling $[14,15]$. According to the analysis of the above finite element, in the discussion of the optimization of the printer's structure, the structure of the 3D printer can be divided into the entire nozzle system and the remaining part of the rack. The maximum deformation of the statics analysis and the natural frequency of the modal analysis are considered as the criteria for the optimization analysis.

\section{Optimization analysis of nozzle system}

\subsection{The influence of structure improvement on the stability of nozzle system}

The nozzle system of the prusal3 type 3D printer can be divided into feeding system and heating forming system. According to the characteristics of modal analysis, in 
order to improve the natural frequency of the nozzle system, in the case of the same stiffness, it should be appropriate to reduce the overall quality of the nozzle system, however, the quality of the nozzle system is largely due to the stepper motor in the feeding system, whose function is to provide feed power for the feeding system. In the process of improvement, the nozzle system of feeding system and heating molding system are divided, and it is to use the principle of remote feeding. The feeding system is connected to the heating system by the engineering plastic conduit, when the printer works, the printed material is sent through the tube to the heating melting system. The feeding system can be placed as a separate part next to the printer or a part fixed to the frame of the $3 \mathrm{D}$ printer. In order to verify the feasibility of the method, the nozzle is firstly separated, and then the nozzle system of the printer before and after separation is calculated to do the statics analysis. The resulting static analysis of the deformation shown in Fig.4 (a) (b) below:

(a)

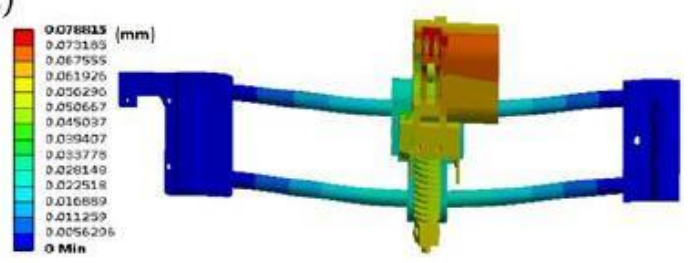

(b)

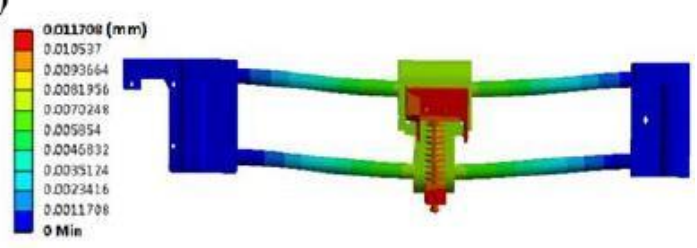

Figure 4. The overall deformation of the nozzle system before separation and after separation

From the static analysis in Fig.4, it can be seen that the largest deformation of the nozzle system before separation is $0.0788 \mathrm{~mm}$, and the largest deformation after separation is $0.0117 \mathrm{~mm}$. The amount of deformation of the nozzle system after the initial separation compared to before separation has greatly changed.

In view of the improved effect of the statics analysis of the separated nozzle, the design of the nozzle part is optimized. During the working process of the 3D printer, the temperature of the melted PLA is between 180-210 degrees centigrade, and the cooling fan is located on both sides of the heating nozzle. The temperature on the surface of the nozzle is sampled with an infrared thermometer, and the temperature is measured at 47.6 degrees near the fixed end of the nozzle. From the finite element analysis of the whole machine on the $3 \mathrm{D}$ printer above, it is known that the fixed part of the material with PLA does not show a larger amount of deformation. Combining the properties of PLA materials, it can be seen that at the working conditions of the 3D printer, the PLA does not show any signs of distortion and melting as a fixed material at the bottom of the nozzle heating system. In summary, PLA meets the requirements of designing nozzle-aided fixed brackets in terms of mechanical strength and temperature resistance.

The model of the heating nozzle is shown in Fig. 5 (a).

According to the shape of the nozzle, when the auxiliary fixed bracket is designed, the surface profile of the auxiliary fixed bracket is should matched with the surface of the heating nozzle tail to prevent the heating nozzle from moving during the printer's work, which may lead to the offset of the printed material. In addition, during the design process, the designed auxiliary fixed bracket should satisfy the symmetrical distribution. According to the literature data, it is found that the symmetrical mechanical structure could help to improve the natural frequency of the structure itself. A well designed section of the fixed bracket for the heating part of the nozzle is shown in Fig.5 (b).

(a)

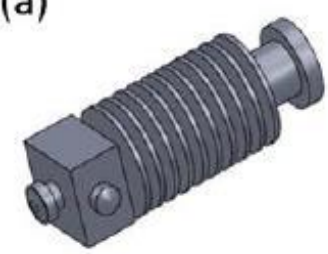

(b)

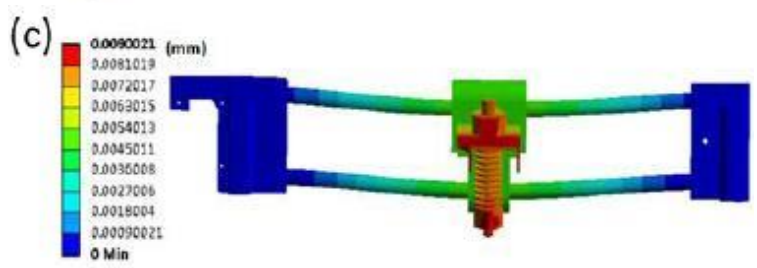

Figure 5. (a)Printer head model and (b)fixed bracket profile And (c)the static analysis of the 3D print nozzle system after the bracket is fixed

The designed fixed bracket and the heating nozzle part are assembled, and the static mechanical analysis of the finite element is carried out. The analysis results are shown in Fig .5(c).

After the installation of the designed fixed bracket, it can be seen from the Fig.5(c) that the maximum deformation of the nozzle system is $0.0090 \mathrm{~mm}$, therefore, the maximum deformation of the nozzle system before the separation, after the separation and after the designed fixed bracket installed are shown in table 2 .

Table 2. The maximum deformation data table for static analysis

\begin{tabular}{cccc}
\hline $\begin{array}{c}\text { Nozzle system } \\
\text { state }\end{array}$ & $\begin{array}{c}\text { Before the } \\
\text { separation }\end{array}$ & $\begin{array}{c}\text { After the } \\
\text { separation }\end{array}$ & $\begin{array}{c}\text { Designed } \\
\text { fixed } \\
\text { bracket } \\
\text { installed }\end{array}$ \\
\hline $\begin{array}{c}\text { The maximum } \\
\text { deformation } \\
(\mathrm{mm})\end{array}$ & 0.0788 & 0.0117 & 0.0090 \\
\hline \hline
\end{tabular}

The frequency analysis of the finite element modal analysis of the nozzle system in the three cases is shown in Fig.6 


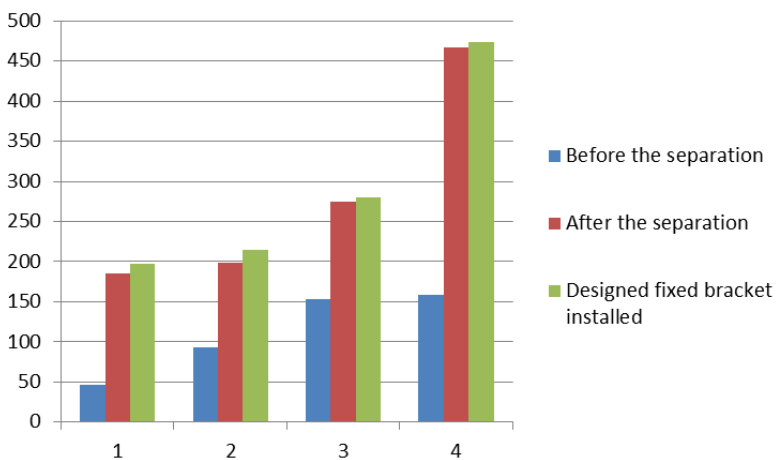

Figure 6. Frequency contrast diagram of modal analysis in 3 cases

From the analysis results, it can be seen that after the designed fixed bracket installed, the overall deformation of the nozzle system obtained is smaller than before separation and after separation, the natural frequency of each order is also greatly improved compared to the before and after separation.

\subsection{Influence of changing level shaft bearing properties on the nozzle system}

The level shaft bearing plays an important role in the load-bearing and modeling process of the printer. In order to improve the structural stability of $3 \mathrm{D}$ printer, the diameter and material of the level shaft bearing is experimentally explored after the designed fixed bracket installed. When the level shaft bearing material and diameter is changed, the response of the nozzle system in statics and dynamics analysis is discussed.

When analyzing the influence of changing the level shaft bearing material on the stability of the printer nozzle system, the material of level shaft bearing is set up as titanium alloy, copper alloy, bearing steel and material property as shown in table 3 .

Table 3. Material properties of level shaft bearing

\begin{tabular}{cccc}
\hline \hline $\begin{array}{c}\text { Type of } \\
\text { material }\end{array}$ & Density $\left(\mathrm{Kg} / \mathrm{m}^{\wedge} 3\right)$ & $\begin{array}{c}\text { Poisson } \\
\text { ratio }\end{array}$ & $\begin{array}{c}\text { Modulus of } \\
\text { elasticity } \\
(\mathrm{Gpa})\end{array}$ \\
\hline $\begin{array}{c}\text { titanium } \\
\text { alloy }\end{array}$ & 4620 & 0.36 & 96 \\
$\begin{array}{c}\text { copper alloy } \\
\text { bearing steel }\end{array}$ & 8300 & 0.34 & 110 \\
\hline \hline
\end{tabular}

When comparing the influence of changing the level shaft bearing diameter on the stability of the nozzle system, the diameter is set to $6 \mathrm{~mm}, 8 \mathrm{~mm}$, and $10 \mathrm{~mm}$. The properties of the nozzle system are set up, and the statics analysis of finite element is carried out.

When changing material properties, the maximum deformation of the nozzle system is shown in the table 4 .

Table 4. The maximum deformation of the nozzle system on different material properties

\begin{tabular}{cccc}
\hline \hline Type of material & $\begin{array}{c}\text { titanium } \\
\text { alloy }\end{array}$ & $\begin{array}{c}\text { copper } \\
\text { alloy }\end{array}$ & $\begin{array}{c}\text { bearing } \\
\text { steel }\end{array}$ \\
\hline $\begin{array}{c}\text { The maximum } \\
\text { deformation }(\mathrm{mm})\end{array}$ & 0.0118 & 0.0126 & 0.009 \\
\hline \hline
\end{tabular}

When changing the nozzle diameter, the maximum deformation of the nozzle system is shown in the table 5 .
Table 5. The maximum deformation of the nozzle system on different diameter of level shaft bearings

\begin{tabular}{cccc}
\hline \hline $\begin{array}{c}\text { Diameter of level } \\
\text { shaft bearing }(\mathrm{mm})\end{array}$ & 6 & 8 & 10 \\
\hline $\begin{array}{c}\text { The maximum } \\
\text { deformation }(\mathrm{mm})\end{array}$ & 0.0147 & 0.0090 & 0.0089 \\
\hline \hline
\end{tabular}

The modal frequencies from first to fourth orders of different material properties and diameters are taken during the dynamic finite element analysis. The results are as follows Fig. 7 .

In the analysis of different diameters about level shaft bearing, the material is structural steel, and in the analysis of different material properties of level shaft bearing, the diameter is $8 \mathrm{~mm}$.

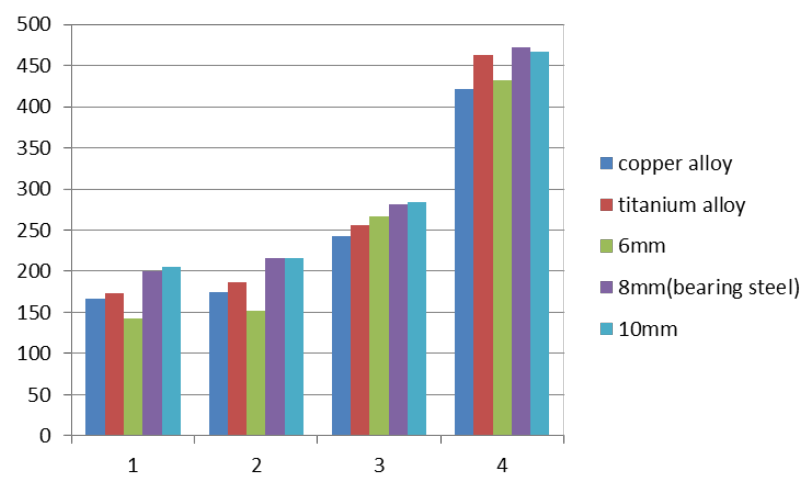

Figure 7. Modal frequency comparison of level shaft bearings under different conditions

It is known from the statics analysis that in the same diameter of the level shaft bearing, the deformation of the material of structural steel is the smallest. At the same time, in the modal analysis of finite element, the modal frequencies from first to fourth orders is higher than other materials. When the material of the level shaft bearing is the same and the diameter is changed, the deformation of nozzle system shows a decreasing trend with the increase of the diameter. There is little difference in the static deformation of the level shaft bearing diameter between $8 \mathrm{~mm}$ and $10 \mathrm{~mm}$, but in the finite element dynamic analysis, modal frequency presents an increasing trend. Meanwhile, when the diameter of the level shaft bearing is from $8 \mathrm{~mm}$ to $10 \mathrm{~mm}$, the increment of the modal frequency is not much, and at the four order modal frequency, the diameter of the level shaft bearing of $8 \mathrm{~mm}$ is greater than the diameter of $10 \mathrm{~mm}$.

It can be seen from the analysis of the conclusion that is no clear relationship between static deformation and the single material property of the level shaft bearing. From the single density, Poisson's ratio, elastic modulus of materials is difficult to judge the final applicability.

For the diameter of the level shaft bearing, when the other conditions are constant, the diameter of the optical axis is not very suitable to increase endlessly, normally, the increase of level shaft bearing diameter helps to improve the bearing capacity and modal frequency of the nozzle system. At that time, it reaches a certain limit value, the effect of the level shaft bearing diameter would not be very obvious, therefore, in the flowing study, the material of the optical axis is set up to the structure steel, and the diameter is $8 \mathrm{~mm}$. 


\section{The overall structural optimization of the 3D printer}

\subsection{Theoretical optimization design of mechanical structure}

From the overall structure static finite element analysis of $3 \mathrm{D}$ printer, it can be seen from the Fig2.(b) that the deformation of the platform is asymmetrical. The main reason is that the supporting bearing under the forming platform is asymmetrical, and it a fixed linear bearing needs to be added on the larger deformation side of the platform to ensure a good symmetry of the forming platform. In addition, before the optimization of the 3D printer, it can be obtained from the first to fourth modal frequencies that the two side columns and beams of the $3 \mathrm{D}$ printer have a more serious phenomenon of vibration. And in the statics analysis Fig2.(a), it is also found that the deformation of $3 \mathrm{D}$ printer's column is still about $0.01 \mathrm{~mm}$ to $0.03 \mathrm{~mm}$.

In order to solve these problems, the columns on both sides of the printer are symmetrically fixed by 2020 aluminum alloy material, finally, the whole frame of the $3 \mathrm{D}$ printer is square. On this basis, after the designed fixed bracket installed, the nozzle system is fixed on the whole frame of the printer.

The finite element analysis of the statics and dynamics of the overall $3 \mathrm{D}$ printer structure is carried out, and the deformation of the overall structure statics analysis of the optimized printer is shown in Fig.8.
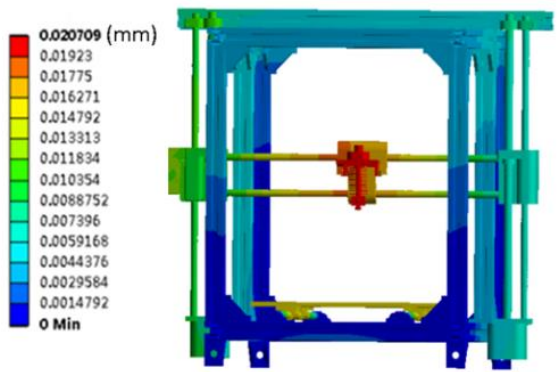

Figure 8. Improved deformation of the overall structure of the $3 \mathrm{D}$ printer

It can be seen from the static analysis of the overall structure that the largest deformation of the optimized 3D printer is $0.0207 \mathrm{~mm}$, located at the nozzle system. Compared with the previous deformation of $0.117 \mathrm{~mm}$, the statics deformation of the optimized 3D printer has been better improved. The overall structure modal analysis of optimized printer is shown in Figure 9.

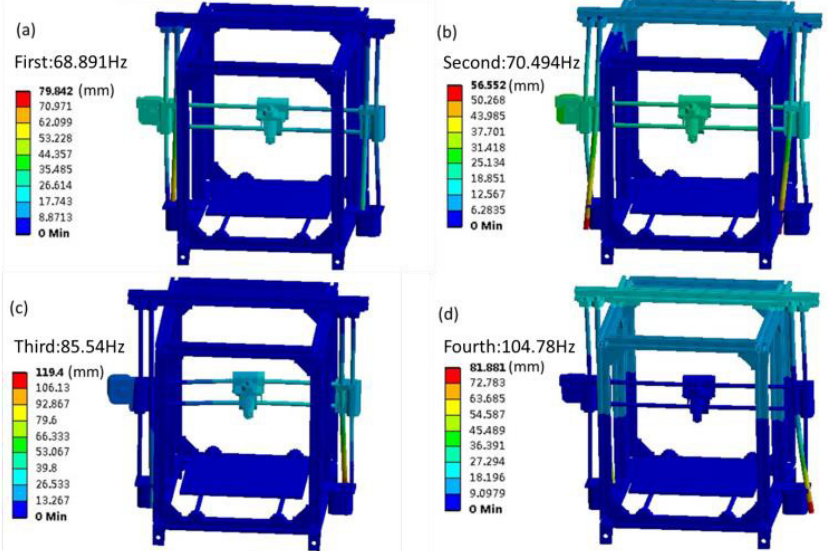

Figure 9. The overall modal analysis of the improved 3D printer

In the result of modal analysis, the $3 \mathrm{D}$ printer's natural frequency of each order is higher than that of the original structure. When the vibration modes are observed at each order of nature frequency, at a lower frequency, there is no serious vibration in the column and beam of the improved 3D printer structure, and only at the second and fourth order natural frequency, there is a small vibration at the beam. In addition, the forming comparison between the before optimized and after optimized of $3 \mathrm{D}$ printers is carried out, it is showed in Figure 10.
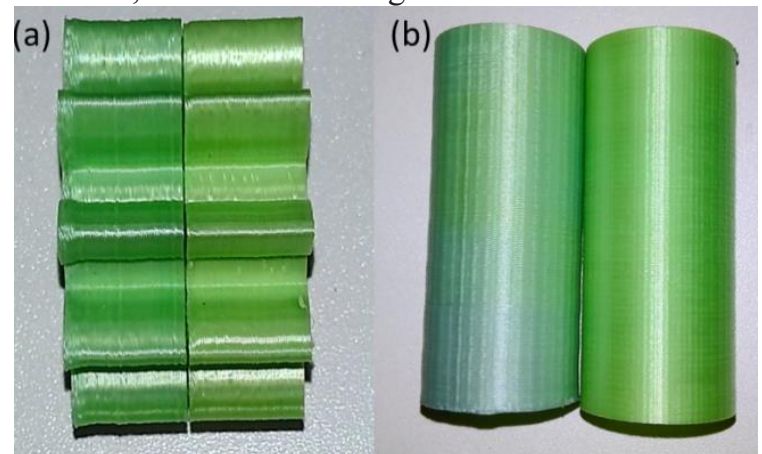

Figure 10. The actual forming contrast of 3D printer before and after improvement

The formed object on the right side of the two pictures is formed by the optimized $3 \mathrm{D}$ printer, and the other conditions are the same in addition to the subtle difference in the color of the molding material. As can be seen from the surface accuracy of the formed object, the smoothness of the surface is greatly improved compared to the forming precision of the 3D printer before the optimization.

\section{Summary}

From the overall structure of the 3D printer, the stiffness of the original column auxiliary fixing device is relatively poor, and there is more obvious vibration phenomenon in the finite element analysis. After the optimization of the $3 \mathrm{D}$ printer structure, its overall frame is square, and the natural frequency of each order is greatly improved, the mode of vibration is also more stable, and the maximum deformation of the $3 \mathrm{D}$ printer overall structure is reduced from the $0.117 \mathrm{~mm}$ to the $0.021 \mathrm{~mm}$, the surface plating of the formed object also has a better improvement.

As far as the nozzle system of the $3 \mathrm{D}$ printer, its quality 
should be appropriately reduced during the design process, and it has a great effect on reducing the load of the optical axis and improving the precision. The diameter of the moving level shaft bearing used should be appropriate, when the diameter of the level shaft bearing reaches a certain limit, with the increase of diameter, the dynamic parameters and statics parameters of the nozzle system will not be changed significantly. In addition, when the 3D printer is designed or the related parts are optimized, as far as possible to ensure the structural symmetry, it is important to improve the stability and the forming precision of the 3D printer structure. Moreover, the introduction of vibration in the $3 \mathrm{D}$ printer forming process should be reduced. In a word, after the structure of the printer optimized, the 3D printer has achieved good results in the finite element analysis and the actual modeling.

\section{Acknowledgment}

The project is supported by major scientific and technological projects in Zhejiang Province, No. 2015C01035, Bidding project of the science and Technology Department of Zhejiang Province No.2017C01019, China. I am very grateful to Professor Tingchun Shi for his guidance in writing this essay. And thanks to Yuan Fan, Nannan Sun and Liangliang Lu in literature inquiries

\section{References}

1. B. Berman, "3-D printing: The new industrial revolution," Business Horizons,vol. 55,no. 2, pp.155-162,2012.

2. G. Cesaretti, E. Dini, X. D. Kestelier, V. Collaand L. Pambaguian, "Building components for an outpost on the Lunar soil by means of a novel 3D printing technology," ACTA ASTRONAUT,vol. 93,no. 1, pp.430-450,2014.

3. B. T. Wittbrodt, A. G. Gloverand J. Laureto et al., "Life-cycle economic analysis of distributed manufacturing with open-source 3-D printers," MECHATRONICS, vol. 23,no. 6, pp.713-726,2013.

4. B. M. Tymrak, M. Kreigerand J. M. Pearce, "Mechanical properties of components fabricated with open-source 3-D printers under realistic environmental conditions," MATER DESIGN,vol. 58,no. 6, pp.242-246,2014.

5. M. Merzoug, M. Mazari, L. Berrahaland A. Imad, "Parametric studies of the process of friction spot stir welding of aluminium 6060-T5 alloys," MATER DESIGN,vol. 31,no. 6, pp.3023-3028,2010.

6. C. X. Yue, L. W. Zhangand S. L. Liao et al., "Research on the Dynamic Recrystallization Behavior of GCr15 Steel," Materials Science \& Engineering A,vol. 499,no. 1-2, pp.177-181,2009.

7. A. K. Bledzki, A. Jaszkiewiczand D. Scherzer, "Mechanical properties of PLA composites with man-made cellulose and abaca fibres," Composites Part A Applied Science \& Manufacturing,vol. 40,no. 4, pp.404-412,2009.
8. T. T. Ngoc, G. R. Liu, H. Nguyen Xuanand T. Nguyen Thoi, "An edge - based smoothed finite element method for primal\&ndash;dual shakedown analysis of structures," INT J NUMER METH ENG,vol. 82,no. 7, pp.917-938,2010.

9. S. Shojaee, N. Valizadeh, E. Izadpanah, T. Buiand T. $\mathrm{V}$. $\mathrm{Vu}$, "Free vibration and buckling analysis of laminated composite plates using the NURBS-based isogeometric finite element method," COMPOS STRUCT,vol. 94,no. 5, pp.1677-1693,2012.

10. S. Nikbakht, S. J. Salamiand M. Shakeri, "Three Dimensional Analysis of Functionally Graded Plates Up to Yielding, Using Full Layer-wise Finite Element Method," COMPOS STRUCT,vol. $182,2017$.

11. T. Csanádi, D. Némethand F. Lofaj, "Mechanical Properties of Hard W-C Coating on Steel Substrate Deduced from Nanoindentation and Finite Element Modeling," EXP MECH,vol., pp.1-13,2016.

12. N. Valizadeh, S. Natarajanand O. A. Gonzalez-Estrada et al., "NURBS-based finite element analysis of functionally graded plates: Static bending, vibration, buckling and flutter," COMPOS STRUCT,vol. 99,no. 5, pp.309-326,2013.

13. C. C. Hong, C. L. Changand C. Y. Lin, "Static structural analysis of great five-axis turning-milling complex CNC machine," Engineering Science \& Technology An International Journal,vol. 19,no. 4, pp.1971-1984,2016.

14. Z. Silvayeh, R. Vallantand C. Sommitsch et al., "Influence of Filler Alloy Composition and Process Parameters on the Intermetallic Layer Thickness in Single-Sided Cold Metal Transfer Welding of Aluminum-Steel Blanks," Metallurgical \& Materials Transactions A,vol. 48,no. 11, pp.5376-5386,2017.

15. D. Moensand M. Hanss, "Non-probabilistic finite element analysis for parametric uncertainty treatment in applied mechanics: Recent advances," Finite Elements in Analysis \& Design,vol. 47,no. 1, pp.4-16,2011. 